EVS24

Stavanger, Norway, May 13-16, 2009

\title{
Heuristic Design of Advanced Drives: Analysis of Trade- offs in Powertrain Electrification
}

\author{
E.J.Wilhelm, W.W. Schenler \\ Paul Scherrer Institut, Villigen PSI, CH-5232, Switzerland \\ erik.wilhelm@psi.ch
}

\begin{abstract}
Consumer demand for fuel efficient, low-emission vehicles is growing. This trend is motivated on one hand by the increasing fuel cost and on the other by government incentives and increased awareness. By hybridizing and electrifying powertrains, fuel use may be reduced without a sacrificing drive quality or functionality. Manufacturers are introducing powertrain concepts that avoid asking drivers to compromise, other than with perhaps a slight increase in purchase price. Heuristic design methods are useful for quantifying trade-offs between key stakeholder criteria, particularly for new technologies.
\end{abstract}

Keywords: EV (electric vehicle), HEV (hybrid electric vehicle), fuel cell, powertrain, simulation

\section{Introduction}

Vehicle purchase and operating cost currently drives personal mobility decisions, but environmental criteria are increasingly being considered. Figure 1 shows three year of several key trends in the automotive industry from Greencarcongress.com and Wolfram Alpha [1,2]. Google Trends ${ }^{\mathrm{TM}}$ search volume results show public interest in electric cars overtaking interest in hybrid vehicles, but both taking a 'back seat' to searches for "global meltdown".

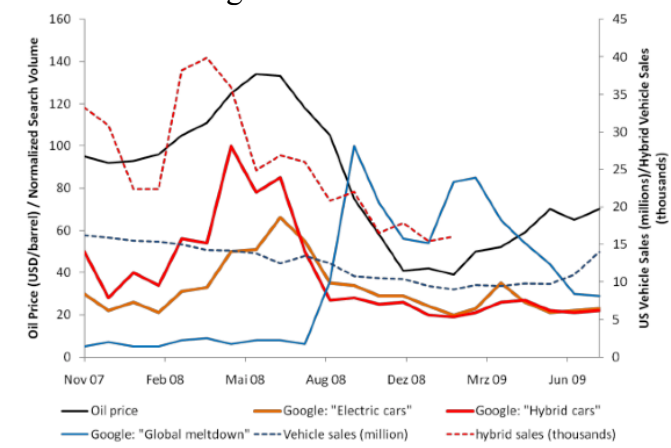

Figure 1: Automotive trends since 2007

\subsection{Trade-off Criteria}

The size/performance versus purchase cost tradeoff is most important criteria for most vehicle consumers. Fuel economy, contrary to common knowledge, is rarely rigorously considered [3]. The challenge for manufacturers and policy makers is to ensure that environmental and social considerations are internalized when drivers choose between available options. Selected stakeholder criteria, listed in Table 1, were quantified in this work.

\begin{tabular}{lll}
\multicolumn{3}{l}{ Table 1: Stakeholder criteria considered } \\
\hline Cost & Production & $\mathrm{CHF}$ \\
& Ownership & $\mathrm{CHF} / \mathrm{km}$ \\
\hline Performance & Acceleration (0-100) & $\mathrm{s}$ \\
& Top Speed & $\mathrm{kph}$ \\
\hline Utility & Range & $\mathrm{km}$ \\
& All-electric range & $\mathrm{km}$ \\
\hline Environment & Direct emissions & $\mathrm{g} / \mathrm{km}$ \\
& Resource use & $\mathrm{kg} / \mathrm{km}$ \\
& Indirect burdens & $\mathrm{kg} / \mathrm{km}$ \\
\hline Safety & Fatality rate & $1 / \mathrm{km}$ \\
\hline
\end{tabular}




\subsection{Heuristic Design Methods}

Vehicle manufacturers prefer to adhere to an incremental design approach which keeps research and development costs low while maximizing the re-use of reliable components in successive design generations, as shown in Figure 2. While the traditional 'tried and true' method is efficient when developing conventional powertrain designs, advanced hybrid and electric powertrains often cannot follow an evolutionary design path. In order to perform an unbiased analysis of effects of introducing various vehicle technologies, heuristic design methods are used to compose sets of vehicle designs according to 'rules of thumb'. These heuristic design rules are based in part on historical architecture design methodologies [4], as well as first principles and physical laws. These methods are particularly useful when examining technology implementation in broad markets as opposed to attempting to extrapolate based on narrow case studies.



Figure 2: Heuristic and incremental design

When composing heuristic rules, it is useful to be able to predict the impact that a particular rule will have on the number of designs in the resulting set. Equation 1 predicts the maximum number of designs that will be present in a set given the number of choices per category. Introducing a rule between two exogenous options results in the removal of the number of designs given by Equation 2, where the variable $\mathrm{d}_{\mathrm{i}}$ represents the option categories not affected by the introduction of the rule. The variable $h_{\text {dep }}$ accounts for the fact that when designing the set, it is difficult to analytically predict the final number of designs $\left(\mathrm{n}_{\mathrm{set}}\right)$ due to the recursive nature of endogenous rule interaction.

$$
\begin{aligned}
n_{\text {tot }}=\prod_{i=1}^{N} s_{i} \\
h_{\text {end }}=\sum_{k=1} \prod_{i=1}^{N-2} d_{i} \mid d_{i} \notin h_{\text {end-rule }} \\
n_{\text {set }}=n_{\text {tot }}-\sum h_{\text {end }}-\sum h_{\text {dep }} \\
n_{\text {tot }}=\text { Total\# of designs } \\
n_{\text {set }}=\text { \#of designs in final set } \\
s_{i}=\text { \# of designs in category } \\
h_{\text {end }}=\text { \#endogenous designs removed } \\
d_{i}=\text { \#sets exclusive heuristic } \\
h_{\text {end -rule }}=\text { sets affected by heuristic } \\
h_{\text {dep }}=\text { \#dependent designs removed }
\end{aligned}
$$

Foreknowledge of the number of designs resulting from implementing heuristic rules maximizes the range of technology variation within the scope of the study.

\section{Design Set}

The options and heuristics used in composing the vehicle designs were tailored to ensure that an investigation into the trade-offs inherent in powertrain electrification could be effectively and fairly examined.

\subsection{Design Options}

A comprehensive table of design options which were used can be found in Appendix A. The options were chosen to reflect the current powertrain technology state of the art. It is also possible to include options that are not currently available to perform 'what-if' analysis, with the advantage of having a technology boundary within which interpolations instead of extrapolations can be performed. The hybrid architectures considered in this work are shown in Figure 3. It is important for the following discussion to note that the hybrid architectures were simulated using the simplification that mechanical and electrical power splitting can be performed interchangeably (i.e. no motor speed or electrical transients are considered). This allows state of charge to be the only control variable for which a control optimization must be performed. 




None

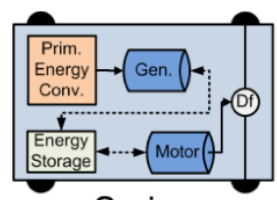

Series

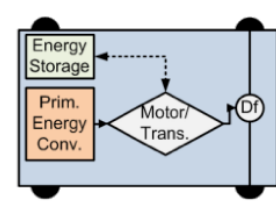

Mild

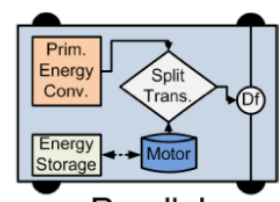

Parallel
Figure 3: Permitted hybridization options

The rules used in developing the design set can be found in Appendix B. They reduced the set of 36288000 possible technology combinations to a manageable 11520 vehicle designs.

\subsection{Life Cycle Inventories}

Wherever applicable, conservative assumptions have been made in favour of optimistic ones. Unfortunately in-service life cycle cost data is currently difficult to obtain for all-electric and fuel cell vehicles, however initial reports suggest that hybrid vehicles are marginally more expensive to maintain than non-hybrid variants of the same model [5]. Assumptions about advanced technology cost were based on Kromer's work [6], and basic cost data from the Touring Club Suisse [7] and GM [8]. Life cycle environmental data comes from the GREET model [9], and was adapted to the vehicle designs in this study based primarily on weight and materials and validated against the ecoinvent life-cycle database for selected technology options [10]. The electricity mix in the analysis was taken to be the US average, and standard GREET $1.8 \mathrm{c}$ and 2.7 assumptions were accepted when building the well-to-tank and vehicle cycle emissions and energy use models.

\subsection{Hybrid Control Optimization}

In order to objectively compare vehicle technology, it is critical to ensure that energy use variation caused by hybrid powertrain control is minimized. In principle, powertrain control can influence almost every criteria of interest. For example, automatic transmission shifting control impacts acceleration, consumption, drivability, noise, etc. For this work, the primary interest is in optimizing the control of the power split for hybrid vehicles, since this has the largest effect on the vehicle's energy consumption and hence influences the greatest number of parameters [11]. The power split for a hybrid powertrain is defined in equation 4, where the ratio of the torque provided by the motor to the total torque required to drive the wheels is linearly correlated to the power provided by the electrical path over the total power required to drive the vehicle.

$$
U_{\text {opt }}(x, t)=\frac{P_{\text {motor }}}{P_{\text {total }}} \in\{-1 \ldots 1\}
$$

A visualization of a dynamic programming result is shown in Figure 4, where the state variable $\mathrm{X}$ representing the hybrid battery state of charge is plotted on the ordinate, the drive cycle time $t$ is plotted on the abscissa, and the state of charge shown for various trajectories. The black and white grid defines the optimal control raster. The final time $t_{f}$, having the lowest cost (lowest fuel consumption), is worked backwards to the start of the New European Driving Cycle (NEDC), always choosing the minimum cost path. For more information on using dynamic deterministic programming to optimize hybrid control, please refer to the work of Sundström or Baotić $[12,13]$.

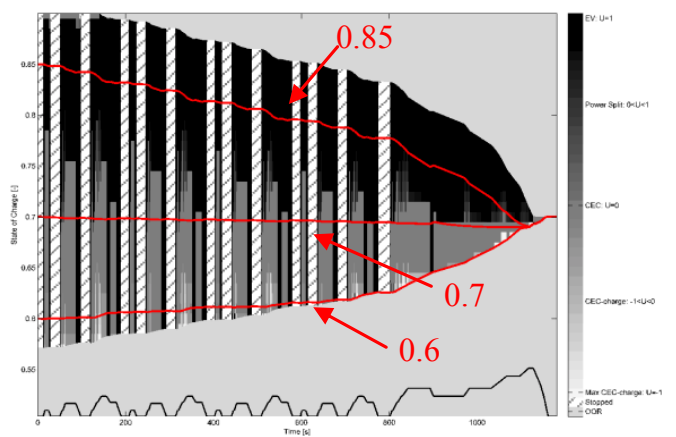

Figure 4: Three NEDC runs with 85,70 , and $60 \%$ starting states of charge

The cost function can also be formulated to include multiple terms, including minimizing state of charge variation, but the most effective way to implement the algorithm is to use a 'hard finish' approach to set the maximum variation that the state of charge may have from its initial value at $0.5 \%$, and to use fuel energy consumption as the only minimization term. A major advantage of ensuring state of charge neutrality is that different hybrid architectures may be compared without applying contentious assumptions about driver charging and uses patterns [14]. 


\section{Analysis of Results}

Fuel consumption is a function of vehicle mass, size, degree of hybridization, and engine displacement among other things. The distribution of the design set by energy consumption is shown in Figure 5. The general trend of clustering by engine size shown in the figure pervades the results analysis. Heuristic rules dictate that series hybrids have batteries sized for plug-ins, although do not achieve energy consumption of all-electric operation because of the state-of-charge neutrality constraint imposed through the optimal control algorithms.



Figure 5: Aggregation by architecture in set

Table 2 provides criteria averages to put the various results into perspective.

Table 2: Design set criteria averages

\begin{tabular}{|l|c|c|c|}
\hline Acceleration time (s) 0-100 kph & 8.8 & 17.5 & 3.8 \\
\hline Maximum Velocity (kph) & 220 & 281 & 184 \\
\hline Purchase price (2008 USD) & 32700.00 & 44200.00 & 16500.00 \\
\hline Fuel Consumption (Gas. Equiv. L/100km) & 5.6 & 13.5 & 0.9 \\
\hline Greenhouse Gas Emissions (g/km) & 171 & 400 & 32 \\
\hline NOx Emissions (g/km) & 0.2 & 0.4 & 0.1 \\
\hline
\end{tabular}

Average fuel consumption and life-cycle $\mathrm{CO}_{2}$ emissions are lower than current North American fleet averages due to the strong representation of alternative powertrains in the design set. NOx emissions are higher than present maximum allowable tailpipe emissions, on the other hand, because of the fact that life-cycle emissions are calculated $[15,16]$.

The sensitivity of fuel consumption to vehicle weight is reduced through hybridization, as shown by the relative slopes of the lines in Figure 6. This is a direct result of the energy recaptured during regenerative braking reducing inertial losses, and increased powertrain efficiency. This trend is shown both for simulated results (HVM sim.) as well as for real world data from the German ADAC and from a fleet of 28 different electric vehicles operating in Mendrisio, Switzerland [17,18].



Figure 6: Hybrids are less sensitive to weight reduction than conventional vehicles

The trade-off between fuel consumption and performance is quantified in Figure 7. Drivers typically place much more importance on high performance, often characterized by $0-100 \mathrm{kph}$ acceleration time [19]. Figure 8 shows that as hybridization ratio increases (i.e. a larger electric motor and battery are present) acceleration time is reduced slightly, while fuel consumption is reduced drastically. This explains how the tradeoff between performance and consumption is optimally reconciled, or 'dominated' by parallel hybrids with high hybridization ratios.

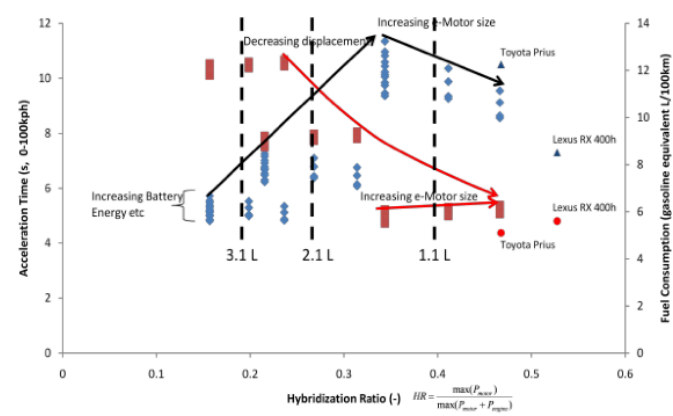

Figure 7: Drivers must not sacrifice much performance to achieve lower fuel consumption

Lowering vehicle NOx emissions is of interest to regulators who set maximum limits which manufacturers must meet with increasingly complex exhaust and engine control systems. This conflicts with the manufacturer's need to produce high performance vehicles to satisfy consumer demand. The dashed trend line closest to the origin in Figure 8 represents the Pareto optimal design set, and in the case of compact, passenger 
vehicles, corresponds to non-hybrids. Although this result appears to contradict the previous fuel consumption versus acceleration assertion, it must be pointed out that when considering full life-cycle NOx emissions, hybrid vehicles suffer from increased manufacturing and end-of-life emissions while offering only modest improvements in on-road emissions due to reduced fuel consumption. Modern emissions control technologies [20] are able to hold emission low enough that conventional vehicles may even compete with hydrogen fuel cell vehicles on a per-km basis when hydrogen is produced centrally through steam methane reforming (SMR). Fuel cell vehicles using photovoltaic hydrogen offer the lowest emissions, but tend towards lower performance, while electric vehicles suffer from significant manufacturing NOx emissions.



Figure 8: Fuel cell vehicle emissions are strongly dependent on fuel feedstock

One of the largest barriers to wide-spread adoption of all-electric vehicles is the consumer requirement for autonomy of over $300 \mathrm{~km}$. The optimal trade-off curve for range versus lifecycle greenhouse gas emissions is shown in Figure 9. The fuel cell vehicle designs are fueled with $\mathrm{PV} \mathrm{H}_{2}$, an assumption that has a decisive impact on total emissions.

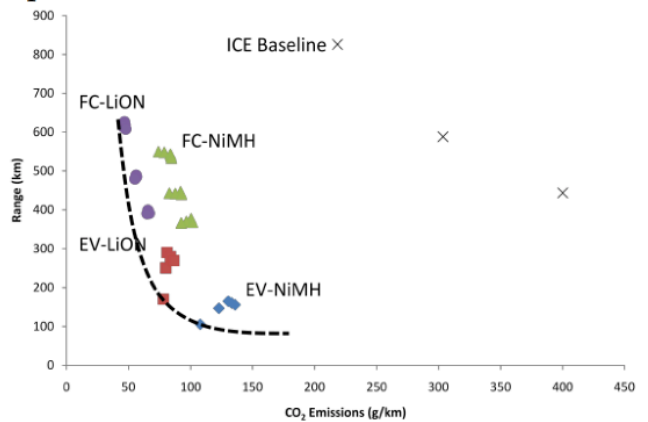

Figure 9: PV-hydrogen based fuel cell vehicles and small-battery EV's dominate range $/ \mathrm{CO}_{2}$ curve
The main result is that baseline combustion vehicles still offers the largest autonomy but emit much more life-cycle $\mathrm{CO}_{2}$. Fuel cell vehicles using hydrogen from solar PV could still satisfy driver autonomy requirements while emitting much less. Another result of interest is that, based on the GREET database and optimized simulation results, lithium ion chemistry is consistently superior to NiMH chemistry with regards to both $\mathrm{CO}_{2}$ and autonomy.

\section{Conclusions}

To objectively analyze the impact that electric powertrain technologies have on light duty vehicles, a design set has been composed according to heuristic rules. These heuristic methods allow the performance of previouslyuntried combinations of powertrain and control technologies to be studied. The design set was then rigorously simulated, and the results were used to evaluate performance using key criteria such as environmental impact, performance, and cost, among others. The conclusions that were reached are that:

- hybrid vehicles are less sensitive to weight reduction than conventional vehicles,

- powertrain electrification reduces the severity of the trade-off between fuel consumption and performance, with marginal cost increases,

- Electric and fuel cell vehicles offer similar life-cycle environmental trade-offs with respect to performance, provided hydrogen is produced renewably,

- Fuel cell vehicles incur greater cost, but offer range advantages over all-electric vehicles.

\section{Acknowledgments}

This work has been supported by the Swiss Competence Center Energy and Mobility (CCEM$\mathrm{CH}$ ), in collaboration with MIT and industrial partners under the framework of the Alliance for Global Sustainability. 


\section{References}

[1] "vehicle sales - Wolfram|Alpha," Wolfram Alpha, Oct. 2009.

[2] "US Hybrid Sales in February Drop 29\%; Lower Decline Than General LDV Market," Green Car Congress, Mar. 2009.

[3] Thomas S. Turrentine and Kenneth S. Kurani, "Car buyers and fuel economy?," Energy Policy, vol. 35, 2007, pp. 1213-1223.

[4] J.M.Weaver, K. Muci-Küchler, and S. Kamali, "Heuristics for Architecting Automobiles and Automotive Systems: Educating the Next Generation of Automotive System Architects," Proceedings of the 2005 SAE World Congress, Detroit, Michigan: SAE international, 2005.

[5] Jamie Coleman, "Hybrid Repairs Command a (Small) Premium - Lexus Reports," Lexus Reports, Feb. 2009.

[6] Matthew A. Kromer and John B. Heywood, "A Comparative Assessment of Electric Propulsion Systems in the 2030 US Light-Duty Vehicle Fleet," SAE Technical Paper Series, Detroit, Michigan: 2008.

[7] infotech, "TCS - Autokatalog," Touring Club Suisse, 2009.

[8] General Motors, "GM Vehicle Comparison Tool," GeneralMotors.com, 2009.

[9] Argonne National Laboratory, "Argonne GREET Model 1.8c.0 \& 2.7,” 2009.

[10] “Ecoinvent Database," ecoinvent.ch, Sep. 2009.

[11] Olle Sundstrom, Lino Guzzella, and Patrik Soltic, "Optimal Hybridization in Two Parallel Hybrid Electric Vehicles using Dynamic Programming," Proceedings of the 17th World Congress, Seoul, Korea: 2008, pp. 4642-4647.

[12] Olle Sundström, Daniel Ambühl, and Lino Guzzella, "On Implementation of Dynamic Programming for Optimal Control Problems with Final State Constraints," Les Rencontres Scientifiques de l'IFP - Advances in Hybrid Powertrains, 2008.

[13] Mato Baotic, Frank J. Christophersen, and Manfred Morari, "Constrained Optimal Control of Hybrid SystemsWith a Linear Performance Index," IEEE Transaction on Automatic Control, vol. 51, Dec. 2006.

[14] Michael Duoba, Richard Carlson, Forrest Jehlik, John Smart, and Sera White, "Correlating Dynamometer Testing to In-Use Fleet Results of Plug-In Hybrid Electric Vehicles," EVS-24, Stavanger, Norway: 2009.

[15] NHTSA, “C.A.F.E. Overview,” 2009.
[16] US EPA, "EPA Emission Standards,” 2009.

[17] National Highway Traffic Safety Administration, TRAFFIC SAFETY FACTS 2006, National Center for Statistics and Analysis: National Highway Traffic Safety Administration, 2006.

[18] Karl Meier-Engel, Measurement of the energy consumption on the test stand of the HTA Biel, HTA Biel: Swiss energy, 1999.

[19] Lynette Cheah, Christopher Evans, Anup Bandivadekar, and John Heywood, Factor of Two: Halving the Fuel Consumption of New U.S. Automobiles by 2035, Cambridge, Mass., USA: Sloan Automotive Laboratory, Massachusetts Institute of Technology, 2007.

[20] John B. Heywood, Internal Combustion Engine Fundamentals, New York: Mcgraw-Hill Ise, 1989.

\section{Authors}

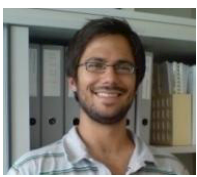

Erik Wilhelm is working towards his $\mathrm{PhD}$ from the ETH Zurich in the Technology Assessment group (GaBE) at the Paul Scherrer Institut. His focus is on advanced powertrain simulation and heuristic vehicle design. The results of this research will be applied for policy analysis using multi-criteria analysis. He has an Honours Bachelor and Masters of Chemical Engineering from the University of Waterloo.

Warren Schenler did his undergraduate studies in engineering physics at Oregon State University, and graduate studies in Technology and Policy, Operations Research, and Energy Systems Analysis at the Massachusetts Institute of Technology. He came to Switzerland to work at the ETH Zurich on energy research projects studying electric power system issues in Switzerland, Romania and China, and has continued this work at the Paul


Scherrer Institut in the Technology Assessment group. His research interests also include transportation, geothermal and hydrogen energy systems. 
Appendix A: Technology Options

\begin{tabular}{|c|c|c|c|c|c|}
\hline Option Category & Options & & & & \\
\hline Classes & 3 & compact sedan & midsize sedan & midsize pickup truck & \\
\hline Markets & 2 & passenger & sport & & \\
\hline Engines & 3 & otto & diesel & fuel cell & \\
\hline Hybridization & 5 & none (combustion) & mild & plug-in series & parallel all-electric \\
\hline Body Structures & 4 & steel & high-S steel & aluminum & composite \\
\hline Fuels & 4 & gasoline & diesel & hydrogen & electricity \\
\hline Displacements (L) & 12 & $1.0,1.1,1.7,1.9,2$ & $.0,2.1,2.7,2.9,3$. & , 3.1, 3.7, 3.9 & \\
\hline Fuel Cell Powers (kW) & 3 & $30,40,50$ & & & \\
\hline Electric Path Power (kW) & 10 & $3,30,40,50,60,70$ & $0,80,90,100,110$ & & \\
\hline Secondary Chemistry & 2 & $\mathrm{NiMH}$ & LION & & \\
\hline Secondary Energy (Ah) & 7 & $4.5,30,40,50,60$ & 70,80 & & \\
\hline Fuel Storage Type & 5 & $60 \mathrm{~L}$ & $90 \mathrm{~L}$ & $120 \mathrm{~L}$ & 350 bar \\
\hline Total: & $3628800 \mathrm{C}$ & & & & \\
\hline
\end{tabular}

Appendix B: Heuristic Design Rules

\begin{tabular}{|c|c|c|}
\hline Endogeneous Options & Dependent Endogeneous Options & Assumptions \\
\hline $\mathrm{Cl}$ uses diesel & mild series hybrids only $0.5 \mathrm{kWh}$ and $3 \mathrm{~kW}$ & Cost \\
\hline SI uses gasoline, hydrogen & parallel hybrids only use 20 and $60 \mathrm{~kW}$ & Compact vehicles have a baseline cost of CHF 21207 \\
\hline FC uses hydrogen & parallel hybrids only use 0.5 and $3 \mathrm{kWh}$ & Midsized vehicles have a baseline cost of CHF 48137 \\
\hline $2.1 \mathrm{~L}$ only for pickup & sport vehicles have $\mathrm{Cd}$ of 0.2 & SUV vehicles have a baseline cost of CHF 67964 \\
\hline sport fuel cell 90kW & passenger vehicles hav $\mathrm{Cd}$ of 0.3 & Average diesel premium paid is CHF 2884 \\
\hline compact fuel cell $65 \mathrm{~kW}$ & luxury vehicles have $\mathrm{Cd}$ of 0.25 & no additional cost for gasoline \\
\hline 2 seating only for sport & compact have base weight of $1096 \mathrm{~kg}$ & cost of hydrogen storage integrated in fuel cell cost \\
\hline \multirow[t]{16}{*}{4 seating only for compact } & midsize have base weight of $1450 \mathrm{~kg}$ & luxury adds a cost premium of CHF 100026 \\
\hline & pickup have base weight of $2062 \mathrm{~kg}$ & sport adds a cost premium of CHF 88892 \\
\hline & no mild series fuel cell hybrids & no cost associated with increased engine displacement \\
\hline & luxury adds $120 \mathrm{~kg}$ & battery and fuel cell costs defined by Kromer [7] \\
\hline & sport subtracts $80 \mathrm{~kg}$ & \\
\hline & compact has frontal area of $2.1 \mathrm{~m}$ & Weight \\
\hline & midsize has frontal area of $2.9 \mathrm{~m}$ & no additional weight variation \\
\hline & pickup has frontal area of $3.3 \mathrm{~m}$ & no additional weight variation \\
\hline & sport fuel cell has only $90 \mathrm{~kW}$ & fuel cell has $360 \mathrm{~W} / \mathrm{kg}$ including hydrogen storage systems \\
\hline & no fuel cell without hybridization & motor adds weight proportional to $1.35 \mathrm{~kW} / \mathrm{kg}$ \\
\hline & mild series hybrids only add power assist in low range & specific power of motor/battery is $0.76 \mathrm{~kW} / \mathrm{kg}$ \\
\hline & & specific energy of battery is $0.06 \mathrm{kWh} / \mathrm{kg}$ \\
\hline & & Other \\
\hline & & displacement correlates linearly with power \\
\hline & & acceleration is linearly related to power and weight \\
\hline & & $\begin{array}{l}\text { idle losses are assumed for non-hybrid powertrains, scaled } \\
\text { with engine size }\end{array}$ \\
\hline
\end{tabular}

